\title{
Xantoma tendinoso normolipémico múltiple en coexistencia con glaucoma terminal bilateral y sindactilia
}

\section{Multiple normolipemic tendinous xanthoma in coexistence with bilateral terminal glaucoma and syndactyly}

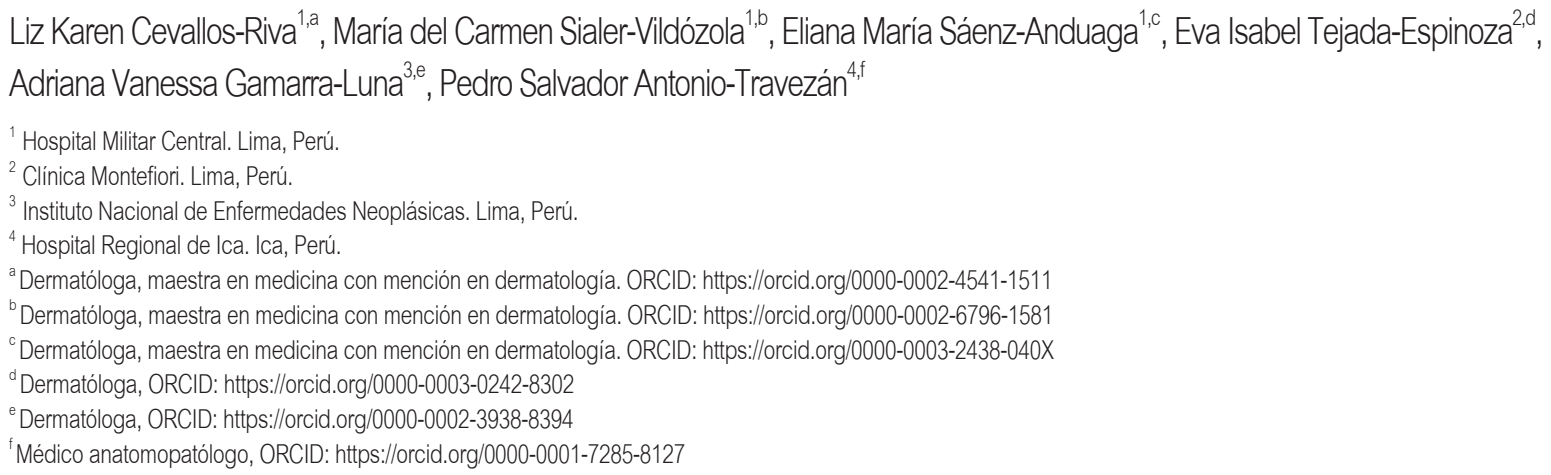

An Fac med. 2020;81(4):436-9. / DOI: https://doi.org/10.15381/anales.v81i4.19683.

Correspondencia:

Liz Karen Cevallos Riva

dralizcevallos@gmail.com

Recibido: 12 de febrero 2021

Aprobado: 30 de marzo 2021

Publicación en línea: 15 de abril 2021

Conflictos de interés: Los autores declaran no tener conflictos de interés.

Fuente de financiamiento:

Autofinanciado

Citar como: Cevallos-Riva L, SialerVildózola M, Sáenz-Anduaga E, Tejada-Espinoza E, Gamarra-Luna A, Antonio-Travezán P. Xantoma tendinoso normolipémico múltiple en coexistencia con glaucoma terminal bilateral y sindactilia. An Fac med. 2020;81(4):436-9. DOI: https://doi. org/10.15381/anales.v81i4.19683.

\section{Resumen}

Los xantomas tendinosos están habitualmente asociados con hiperlipidemia, de ahí que son infrecuentes los xantomas tendinosos normolipémicos. La histopatología de este cuadro es característica por la presencia de células espumosas, hendiduras de colesterol y células de Touton. Presentamos el caso de un paciente varón de 22 años portador de xantomas tendinosos normolipémicos, en coexistencia con glaucoma terminal bilateral y sindactilia donde la histología y la inmunohistoquímica fueron de gran utilidad para el diagnóstico definitivo.

Palabras clave: Xantoma; Glaucoma; Sindactilia (fuente: DeCS BIREME).

Abstract

Tendinous xanthomas are usually associated with hyperlipidemia, normolipemic tendinous xanthomas are uncommon. The histopathology of this condition is characterized by the presence of foam cells, cholesterol clefts, and Touton cells. We present a 22-year-old male patient with normolipemic tendon xanthomas, coexisting with bilateral terminal glaucoma and syndactyly, where histology and immunohistochemistry were very useful to reach the definitive diagnosis.

Keywords: Xanthoma; Glaucoma; Syndactyly (source: MeSH NLM). 


\section{INTRODUCCIÓN}

Los xantomas son placas o nódulos formados por depósitos anormales de lípidos y células espumosas que no representan una enfermedad sino más bien síntomas de distintas enfermedades de las lipoproteínas o pueden aparecer sin un defecto metabólico subyacente ${ }^{(1)}$. Clínicamente, los xantomas pueden clasificarse en eruptivos, tuberoeruptivos o tuberosos, tendinosos o planos ${ }^{(2)}$.

El glaucoma es una neuropatía óptica progresiva que se caracteriza principalmente por una alteración o aumento sostenido de la presión intraocular y una alteración estructural y funcional del ojo ${ }^{(3)}$.

La sindactilia es la fusión del tejido blando y/o hueso entre dedos adyacentes de las manos o pies, provocando una ausencia total o parcial del espacio entre dos dedos que puede presentarse en el recién nacido, por una alteración del desarrollo entre el primer y segundo mes de vida intrauterina o en la edad infantil, secundario a un trauma como quemaduras, o una secuela de heridas complejas de manos o pies que comprometen cicatricialmente los espacios interdigitales ${ }^{(4)}$.

La histología y la inmunohistoquímica permiten el diagnóstico definitivo de múlitples patologías como es el caso de los xantomas tendinosos o sus diagnósticos diferenciales como los dermatofibromas. Presentamos el caso de un paciente con xantoma tendinoso múltiple normolipémico en coexistencia a glaucoma terminal bilateral y sindactilia.

\section{REPORTE DE CASO}

Paciente varón de 22 años, procedente de Ferreñafe, Lambayeque, con antecedentes personales de glaucoma terminal bilateral, ceguera ojo izquierdo y sindactilia de segundo con tercer dedo del pie bilateral. Antecedentes familiares maternos: tía y prima con catarata congénita y otra tía y prima con sindactilia; paternos: abuelo con catarata congénita. Paciente acude al servicio de dermatología con un tiempo de enfermedad de 13 años de inicio insidioso curso progresivo que inicia con tumoraciones en planta de pie izquierdo, posteriormente presentó en forma progresiva tumoración en pie derecho, codo izquierdo, segundo dedo mano izquierda. Los últimos meses aparecieron pápulas en pie izquierdo, muñeca izquierda y codo izquierdo. El examen clínico preferencial evidenció nódulos eritematosos confluentes de aspecto lobulado, superficie lisa, telangiectásica, algo queratósicos de consistencia fibrosa en zona medial y talón de planta de pie izquierdo, y en planta de pie derecho (Figura 1). Tumoración eritematosa circunscrita de superficie lisa, móvil, no dolorosa, de consistencia semidura de aproximadamente $4 \mathrm{~cm}$ de diámetro en codo izquierdo (Figura 2). Tumoración semidura trilobulada de superficie lisa, móvil en región interfalángica proximal de segundo dedo de mano izquierda. Pápulas eritematosas de superficie lisa, en codo, planta izquierda y palma izquierda. Fusión de segundo dedo con tercer dedo de pies bilateral. Eritema palmar bilateral.

Los exámenes auxiliares como hemograma, perfil de coagulación, bioquímica, examen de orina y perfil lipídico fueron normales, el VDRL, ELISA, VIH y antiHBC fueron no reactivos. La ecografía de segundo dedo mano izquierda mostró 2

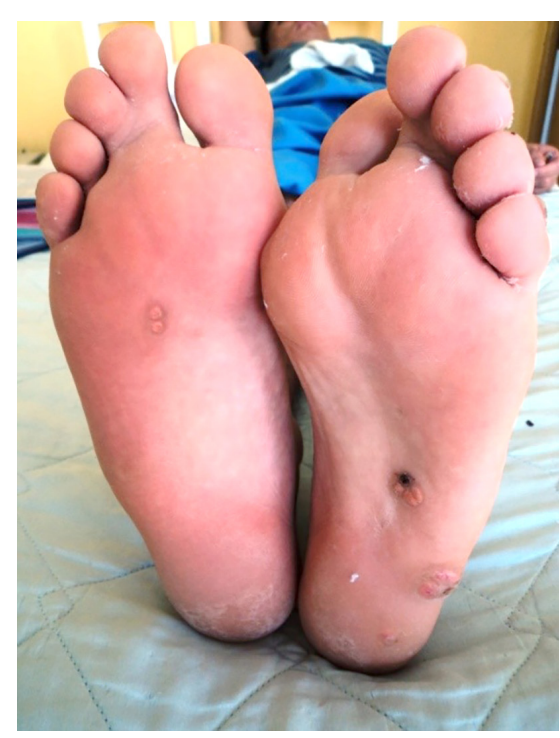

Figura 1. Nódulos eritematosos confluentes de aspecto lobulado, superficie lisa, telangiectásica, queratósica, de consistencia fibrosa en plantas. Se observa zona de toma de biopsia punch en planta izquierda. Se aprecia sindactilia.

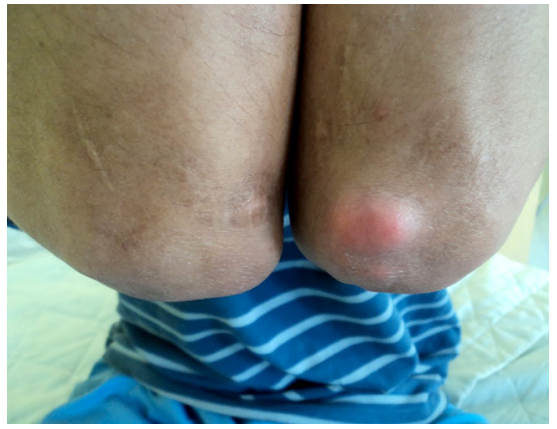

Figura 2. Tumoración eritematosa circunscrita de superficie lisa, móvil, no dolorosa, de consistencia semidura de aproximadamente 4 $\mathrm{cm}$ de diámetro en codo izquierdo

imágenes hipoecogénicas localizadas en tejido celular subcutáneo, sin cápsula, sin calcificaciones. La radiografía de pies fue normal, no se evidenció fusión ósea. La radiografía de codo y mano izquierda mostró que las lesiones cutáneas no comprometen estructuras óseas. El estudio histopatológico de la lesión en planta izquierda con coloración hematoxilina eosina evidenció una epidermis normal, infiltrado denso superficial y profundo en dermis; a mayor aumento, se apreció en la dermis colágeno y fibroblastos formando tractos fibrosos compactos desordenados, células alargadas con núcleo en forma de huso (Figura 3). En la inmunohistoquímica S100 negativo, CD 34 negativo, tricrómica de Masson positivo. La biopsia exéresis de la lesión nodular bien localizada, no encapsulada de codo, con la coloración de HE, mostró cambios localizados en dermis reticular superficial y profunda, formada por macrófagos espumosos asociados con hendiduras de colesterol (Figura 4). La inmunohistoquimica mostró una neta positividad de esas células para el CD68, anticuerpos mono o policlonales: factor XIIla negativo, Mac 387 negativo, proteína S-100 negativo, actina negativo. El Ki67 fue positivo para menos del 2\% de las células de la lesión.

\section{DISCUSIÓN}

El presente caso permitió plantear diversos diagnósticos diferenciales; así, clínicamente se pensó inicialmente en una tumoración fibrohistiocítica, tumor de células gigantes de la vaina tendino- 


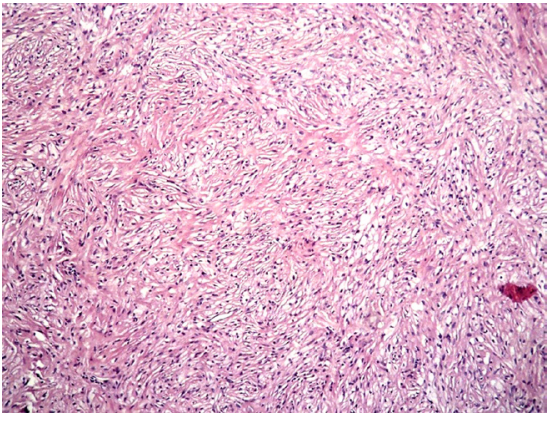

Figura 3. Hematoxilina-eosina, 10X. Dermis poblada por la presencia de colágeno y fibroblastos formando tractos fibrosos compactos desordenados, células alargadas con núcleo en forma de huso.

sa, fibromatosis juvenil, dermatofibroma profundo perforante, fibromatosis plantar, y dermatofibroma eruptivo múltiple. Al realizarse la histopatología en planta izquierda y con la inmunohistoquímica de tricrómico de Masson positivo se planteó dermatofibroma; sin embargo, al obtener CD34 y factor XIIIA negativo se descartó el diagnóstico de dermatofibroma. La presencia de CD 68 positivo para macrófagos, la clínica, la histopatología y la inmunohistoquímica de la lesión del codo nos permitió realizar el diagnóstico de xantoma.

El xantoma se define como la lesión amarillenta, circunscripta, localizada principalmente a nivel del tejido conectivo de la piel, tendones o fascias ${ }^{(5)}$. Existen formas de xantomatosis que se presentan en ausencia de dislipemia ${ }^{(6)}$. Los xantomas pueden dividirse en tres grupos: 1. Xantomas que surgen en pacientes sin trastorno lipídico subyacente. 2. Xanto-

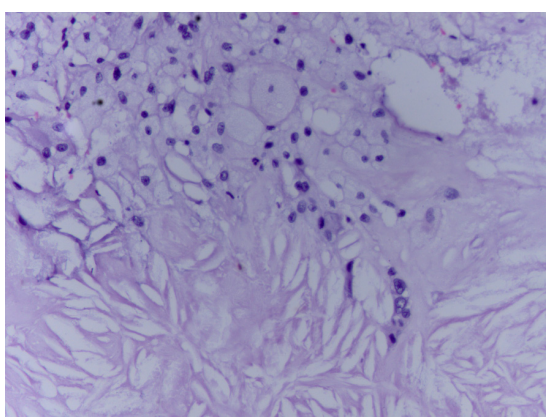

Figura 4. Hematoxilina-eosina, 40X. Células xantomatosas en la parte superior y hendiduras de colesterol en la parte inferior. mas que surgen en un trastorno lipídico primario o hereditario. 3. Xantomas que surgen en pacientes con un trastorno lipídico secundario a otra afección sistémica que involucra metabolismo lipídico desordenado ${ }^{(7)}$. En el caso del paciente, por la topografía y la clínica se trataría de xantomas tendinosos. Los xantomas tendinosos son de varios tamaños y se desarrollan en los ligamentos, fascias y tendones, especialmente en los tendones extensores de las manos, pies y el tendón de Aquiles ${ }^{(2)}$. Con estos tendones ubicados en áreas expuestas a tensión física y trauma, pequeños vasos dentro de ellos filtran lípidos en el tejido conectivo fibroso del tendón ${ }^{(8)}$.

En cuanto a la patogénesis del xantoma tendinoso se ha estudiado la localización y las características histopatológicas de los tejidos xantomatosos en las extremidades de los conejos hiperlipidémicos y se observó una alta incidencia de xantomas en el paratendón plantar del tendón plantar y se postula que el estrés mecánico y la rica vascularización sean factores esenciales para la formación de xantoma en el tendón, y que el macrófago y el endotelio pueden desempeñar un papel importante en la patogénesis ${ }^{(9)}$.

Los xantomas tendinosos están más frecuentemente asociados con hipercolesterolemia familiar heterocigota, pero se ha descrito también en xantoma cerebrotendinoso, b-sitosterolemia, disbetalipoproteinemia familiar (tipo III), colestasis hepática y raramente en individuos normolipémicos ${ }^{(10)}$. Dentro de las principales causas de los xantomas normolipémicos se encuentran la sitosterolemia, xantomatosis cerebrotendinosa, xantoma diseminado, xantogranuloma juvenil, histiocitosis eruptiva e histiocitosis $X{ }^{(11)}$. Se reportan 3 procesos que podrían explicar la patogénesis de la xantomatosis en ausencia de hipercolesterolemia o hiperlipoproteinemia, que son categorizados en tres grupos, el primer grupo incluye desórdenes en la acumulación de lípidos inusuales como colestanol en xantomatosis cerebrotendinosa, o esteroles vegetales en la betasitosterolemia; en el segundo grupo se pueden observar xantomas planos en la cara y en la par- te superior del tronco en pacientes con enfermedades linfoproliferativas como el mieloma múltiple o los linfomas, y el tercer grupo comprende pacientes en quienes se cree que las anomalías locales en la piel desempeñan un papel importante como eritrodermia y epidermolisis bulosa distrófica, xantomas eruptivos generalizados, xantogranuloma juvenil y xantoma diseminatum ${ }^{(12)}$.

El paciente no presentaba otra sintomatología y no se encontró asociación con otras causas descritas en la bibliografía como, por ejemplo, en la xantomatosis cerebrotendinosa ${ }^{(13)}$. Además de sus manifestaciones neurológicas, se describe xantoma tendinoso y alteraciones oftalmológicas, se especifica cataratas y no glaucoma. El caso clínico descrito, tiene el diagnóstico de glaucoma y la asociación xantoma tendinoso con glaucoma no ha sido encontrada. De la misma forma, la sindactilia no se encuentra asociada a xantoma tendinoso. Por lo cual, estos hallazgos en el paciente presentado se consideran como coexistencia.

En la histopatología de los xantomas se aprecian células espumosas en la dermis, a veces células gigantes de Touton, escasos linfocitos o neutrófilos en lesiones más jóvenes, especialmente en xantomas eruptivos, fibrosis o hendiduras de colesterol en lesiones más antiguas ${ }^{(14)}$.

En cuanto al tratamiento de los xantomas, se basa en la reducción de la concentración de lípidos del suero con fármacos que produzcan la regresión de los xantomas. En el caso de los xantomas tendinosos, pueden tardar años en resolverse y el objetivo de reducir los niveles de lípidos es reducir el riesgo de enfermedad cardiovascular ateroesclerótica y pancreatitis, la excisión quirúrgica está indicada en xantomas tendinosos grandes que restringen el movimiento de las articulaciones o cuando hay duda diagnóstica ${ }^{(15)}$. En el caso del paciente, debido a que el colesterol estaba dentro de los rangos normales, no requirió tratamiento médico. Se realizó tratamiento quirúrgico del xantoma tendinoso más grande que se localizaba en codo izquierdo.

Con la presentación del caso se diagnosticó xantoma tendinoso múlitple sin trastorno lipídico subyacente o normolipémico. Considerando que la apari- 
ción de los xantomas tendinosos es muy compatible con el trastorno lipídico, sólo ocasionalmente un paciente presenta xantoma tendinoso con un perfil lipídico normal y las características del paciente no encajaron con ninguna de las causas conocidas o asociadas de xantomatosis normolipémica; por ello, lo infrecuente y la importancia de la presentación de este caso clínico.

\section{AGRADECIMIENTO}

Al Prof. Jorge Arrese, MD, PhD, del Servicio de Dermatopatología del Centro Hospitalario Universitario de Liège de Bélgica por la lectura de la histopatología e inmunohistoquímica del factor XIIla, CD 68, Mac 387, Proteína S-100, Actina y Ki 67 de muestra del codo izquierdo.

\section{REFERENCIAS BIBLIOGRÁFICAS}

1. White L. Xantomatosis y otras enfermedades de las lipoproteinas. En: Wolff K, Goldsmith L, Katz
S, Gilchrest B, Paller A, Leffell D. Fitzpatrick Dermatologia en Medicina General. España: Editorial Médica Panamericana; 2009: 1272.

2. Ponciano D, Cruz J, East C, Bergstresser P. Dermal, subcutaneous and tendon xanthomas: Diagnostic markers for specific lipoprotein disorders. J Am Acad Dermatol. 1988; 19: 95-111. DOI: 10.1016 / s0190-9622 (88) 70157-7

3. Biblioteca de Guias de Práctica Clínica del Sistema Nacional de Salud [Internet]. Grupo de Trabajo de la Guía de Práctica Clínica sobre Glaucoma de Ángulo Abierto. Guía de Práctica Clínica sobre Glaucoma de Ángulo Abierto. Ministerio de Sanidad, Servicios Sociales e Igualdad. Agència de Qualitat i Avaluació Sanitàries de Catalunya (AQuAS) y el Centro Cochrane Iberoamericano (CClb); 2017 [Fecha de acceso: 11 de enero 2020]. Disponible en: https://portal.guiasalud.es/ wp-content/uploads/2018/12/GPC_568_Glaucoma_AQUAS_compl.pdf

4. Zhou J, Chen Y, Cao K, Zou Y, Zhou H, Hu F et al. Classification and matation analysis of a Synpolydactyly kindred. Exp Ther Med. 2014;8: 1569-1574. DOI: 10.3892/etm.2014.1957

5. Corral P, Sáenz B, Sánchez J, Parodi N, Terren A Schreier L. Xantomas y dislipemias, una asociación que no debe pasar desapercibida. Rev Fed Arg Cardiol. 2016; 45(2): 110-113.

6. Iglesias-Puzas Á, Suh-Oh HJ, Flórez Á. Normolipemic eruptive xanthoma in a patient with monoclonal gammopathy of undetermined significance. Med Clin (Barc). 2018 21;151(12):507-508. DOI: 10.1016/j.medcli.2018.03.031
7. Frankel R, Capone R. Xanthelasmas and xanthomas - cutaneous clues to systemic lipid disorders. Clinical Eye and Vision Care. 1995;7(3):117-128. DOI: org/10.1016/0953-4431(95)00122-6

8. Galton D, Krone W. Hiperlipidemia en la práctica. London: Gower Medical Publishing, 1991.

9. Nakano A, Kinoshita M, Okuda R, Yasuda T, Abe M, Shiomi M. Pathogenesis of tendinous xanthoma: histopathological study of the extremities of Watanabe heritable hyperlipidemic rabbits. J Orthop Sci. 2006; 11:75-80. DOI: https://doi.org/10.1007/ s00776-005-0976-7

10. Fleischmajer R, Tint GS, Bennett HD. Normolipemic tendon and tuberous xanthomas. J Am Acad Dermatol. 1981; 5:290-6. DOI: 10.1016 / s0190-9622 (81) $70094-x$

11. Handa R, Gupta K, Wali JP. Normolipemic xanthomatosis. Postgrad Med J. 1995; 71: 555-6. DOI: 10.1136 / pgmj.71.839.555

12. Parker F. Normocholesterolemic xanthomatosis. Arch Dermatol. 1986; 122: 1253-7. DOI: 10.1001/ archderm.1986.01660230045008

13. Castañeda M, Durán C, Cabanillas J. Xantomatosis cerebrotendinosa: Reporte de un caso en el Perú. Evaluación clínica integral y estudios de neuroimágenes. Rev Neuropsiquiatr. 2019; 28(2): 141-149. DOI: https://doi.org/10.20453/rnp.v82i2.3541

14. Rapini R. Practical Dermatopathology. China: Elsevier; 2005.

15. Rekha A, Rai DK. Tendon xanthomas. The Foot. 2010; 20(2-3): 85-6. DOI: 10.1016/j. foot.2010.04.004 